\title{
REASONS FOR DELAYED UTILIZATION OF CATARACT SURGERY AMONG PATIENTS ATTENDING A TERTIARY REFERRAL CENTRE, MAHARASHTRA.
}

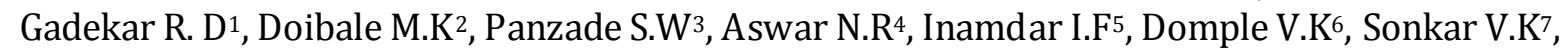
Kulkarni S.K ${ }^{8}$

\section{HOW TO CITE THIS ARTICLE:}

Gadekar RD, Doibale M K, Panzade SW, Aswar NR, Inamdar IF, Domple VK, Sonkar VK, Kulkarni SK. "Reasons for delayed utilization of cataract surgery among patients attending a tertiary referral centre, Maharashtra". Journal of Evolution of Medical and Dental Sciences 2013; Vol. 2, Issue 43, October 28; Page: 8216-8222.

ABSTRACT: BACKGROUND: Cataract is a major cause of vision impairment in many low-income settings. Cataract blindness is a disease which has severe economic repercussions and adversely affects the productivity of country. However, despite rapid increase in the availability of quality services, surgical acceptance is still low in some segments of society. AIM: To study the various reasons for delayed utilization of cataract surgery. METHODS: In this cross sectional study 450 patients above 40 years of age who were admitted in ophthalmology ward for cataract surgery were enrolled by systematic random sampling technique. Socio-demographic data was collected by interviews in local language on predesigned and semi structured proforma. The various reasons for delayed utilization of cataract surgery were asked to them. Statistical tests applied were chi square test and percentages. RESULTS: Majority of the study subjects were illiterate females above 60 years of age belonging to lower socioeconomic status. Most of the study subjects were Hindus from rural area having unilateral blindness. The various reasons for delayed utilization of cataract surgery were economic problems (76.7\%), ignorance by patient $(29.1 \%)$, fear of operation (26.4\%), ignorance by head of family (22.4\%) and suspicion about improvement of vision after surgery $(21.5 \%)$. Some subjects gave reasons as lack of accompanying person, fear of surgery causing death, lack of time, its God will and lack of transport. CONCLUSION: The predominant reason for delayed utilization of cataract surgery was economic constraints. Other reasons were ignorance by patients and head of family, fear of operation and death, suspicion about improvement of vision, God's will, lack of accompanying person and lack of transport.

KEY WORDS: Cataract, Blindness, Economic constraints, Fear.

INTRODUCTION: Cataract blindness is a public health problem of major proportions in the developing world 1 . In South-East Asia Region, cataract is the single most common cause of blindness being responsible for $50-80 \%$ of all blindness. The National Survey on blindness (20062007) shows an estimated $1.0 \%$ prevalence of blindness in general population in India 2 .

Blindness leads not only to reduce economic and social status but may also result in premature death. With the increasing life expectancy and expanding population, the number of cases is expected to increase in the near future ${ }^{3}$. Despite major efforts towards information, education and communication (IEC) by the providers to increase the uptake of surgery by the cataract blind, several barriers at the community level and among individuals continue to hamper the efforts to motivate them for cataract surgery ${ }^{4}$. The concept of avoidable blindness (preventable or curable blindness) has gained increasing recognition during recent years. The eye camp approach to make cataract surgery available has been highly successful and has received wide popular support ${ }^{2}$. 
A global initiative for the elimination of avoidable blindness was launched in February 1999 under the title "Vision 2020- the right to sight" 5 . So this study was planned to identify the reasons for delayed utilization of cataract surgery.

MATERIAL AND METHODS: The present cross sectional study was carried out in ophthalmology ward of Dr. Shankarrao Chavan Government Medical College, Nanded in Maharashtra State, India during January to June 2011. The 450 admitted patients above 40 years of age in the ophthalmology ward for cataract surgery were enrolled for the study after obtaining their informed consent by using systematic random sampling technique. The selected patients were interviewed in local language (Marathi) for data collection in the separate clinical room by the side of ophthalmology ward to avoid the influence of family members or relatives by using predesigned and semi structured proforma. The proforma was included detailed information on socio-demographic factors like age, sex, residence, education, occupation, per capita income and reasons for delayed utilization of cataract surgery. Socio-economic status was determined as per the B. G. Prasad's method for social classification of family ${ }^{6}$. The used operational definition of delayed cataract surgery was 'those patients who were unable to see anything either unilaterally or bilaterally at least for one year in the past due to cataract and were advised for cataract surgery'. Data was tabulated in Microsoft Excel and analysed by using statistical software Open Epi version 2.3 for chi square test and percentages.

RESULTS: Thus we included total 450 study subjects in our study. Out of 450, majority of study subjects, $54.7 \%$ were in the age group of 60 to 69 years followed by $25.1 \%$ in the age group of 50 to 59 years where as $57.3 \%$ were femal es and $42.7 \%$ were males.

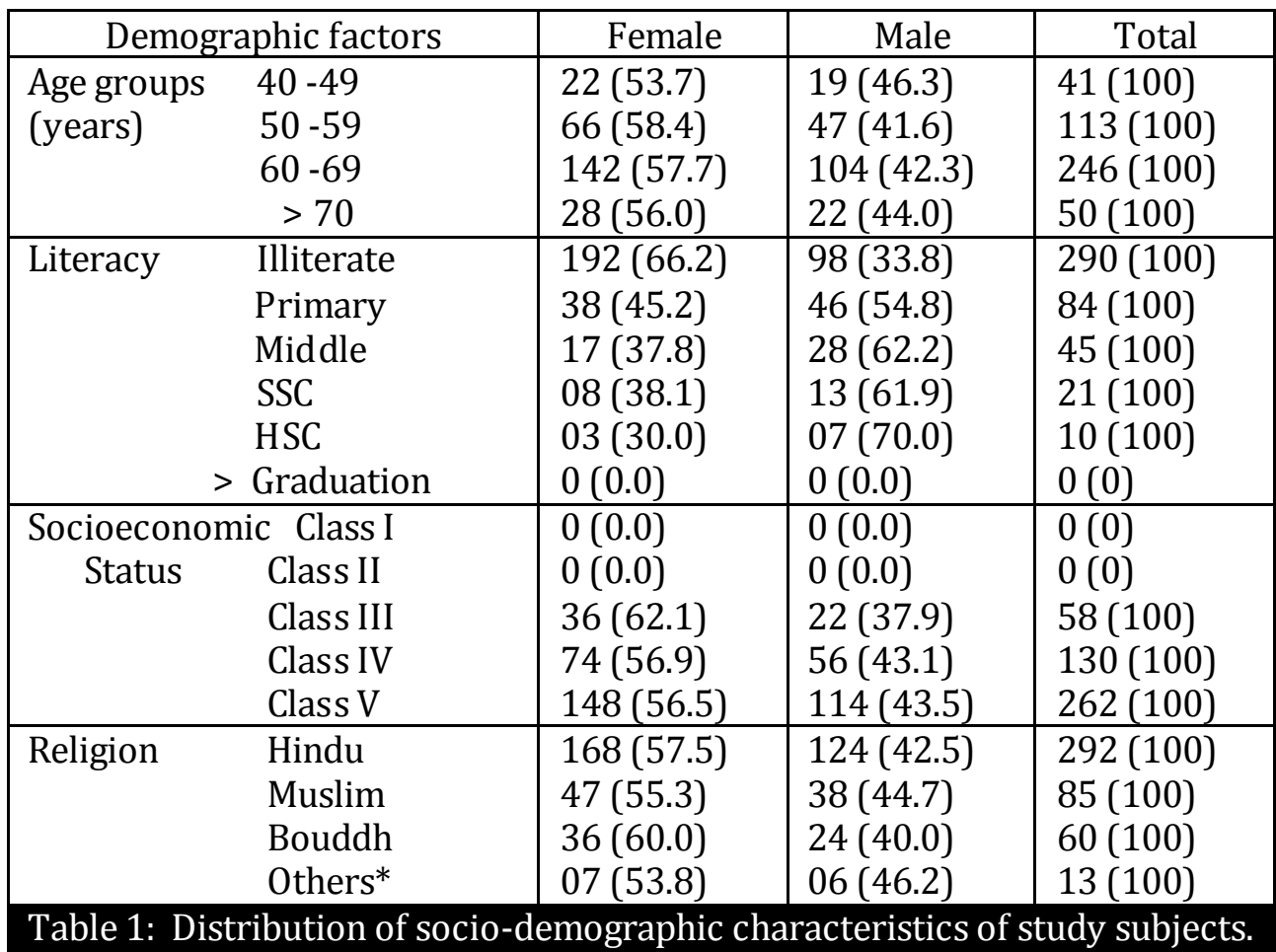


(Figures in parenthesis denote percentages) *Others- Sikh, Christian, Jain

Most of the females (66.2\%) were illiterate compared to males (33.8\%). Highest number of study subjects (58.2\%) was belonged to socioeconomic class V. There was nobody from socioeconomic class I and II.

Maximum study subjects were Hindus (64.9\%), followed by Muslim (18.9\%) and Buddha (13.3\%). Subjects from other religious group were 7 Sikh (1.6\%), 4 Christian (0.9\%) and 2 Jain $(0.4 \%)$ (Table 1$)$.

\begin{tabular}{|c|c|c|c|}
\hline Residence & Female & Male & Total \\
\hline Rural & $186(61.6)$ & $116(38.4)$ & $302(100)$ \\
\hline Urban & $72(48.6)$ & $76(51.4)$ & $148(100)$ \\
\hline Total & $258(57.3)$ & $192(42.7)$ & $450(100)$ \\
\hline
\end{tabular}

Table 2: Relationship between residence and sex of study subjects.

$(\chi 2=6.79, \mathrm{df}=1, \mathrm{P}<0.01) \quad$ (Figures in parenthesis denote percentages)

Maximum study subjects (67.1\%) were from rural area and 32.9\% from urban area. Out of 302 rural subjects, $61.6 \%$ were females and 38.4\% were males. Out of 148 urban subjects, $48.6 \%$ were females and $51.4 \%$ were males (Table 2). The association between residence and sex of the study subjects who were utilizing delayed cataract surgery was statistically highly significant ( $\mathrm{p}<$ 0.01).

\begin{tabular}{|c|c|c|c|}
\hline Cataract & Female & Male & Total \\
\hline Unilateral & $206(56.9)$ & $156(43.1)$ & $362(100)$ \\
\hline Bilateral & $52(59.1)$ & $36(40.9)$ & $88(100)$ \\
\hline Total & $258(57.3)$ & $192(42.7)$ & $450(100)$ \\
\hline
\end{tabular}

$(\chi 2=0.13, \mathrm{~d} \mathrm{f}=1, \mathrm{P}>0.05) \quad$ (Figures in parenthesis denote percentages)

The 80.4\% (362/450) subjects had unilateral blindness and 19.6\% (88/450) subjects had bilateral blindness. Out of unilateral blind subjects, $56.9 \%$ were females and $43.1 \%$ were males whereas 59.1\% females and 40.9\% males were belonged to bilateral blindness (Table 3). The association between sex and cataract in study subjects was not statistically significant $(\mathrm{P}>0.05)$.

\begin{tabular}{|c|l|c|c|c|}
\hline Sr. No. & \multicolumn{1}{|c|}{ Reasons* $^{*}$} & Female & Male & *Total No. \\
\hline 1 & Economic problem & $203(78.7)$ & $142(74.0)$ & $345(76.7)$ \\
\hline 2 & Fear of surgery & $78(30.2)$ & $41(21.4)$ & $119(26.4)$ \\
\hline 3 & Fear of surgery causing death & $34(13.2)$ & $14(07.3)$ & $48(10.7)$ \\
\hline 4 & Ignorance by patient & $82(31.8)$ & $49(25.5)$ & $131(29.1)$ \\
\hline 5 & Ignorance by head of family & $66(25.6)$ & $35(18.2)$ & $101(22.4)$ \\
\hline 6 & $\begin{array}{l}\text { Suspicion about improvement } \\
\text { of vision after surgery }\end{array}$ & $72(27.9)$ & $25(13.0)$ & $97(21.5)$ \\
\hline
\end{tabular}




\section{ORIGINAL ARTICLE}

\begin{tabular}{|c|l|c|c|c|}
\hline 7 & Lack of transport & $18(07.0)$ & $12(06.2)$ & $30(06.7)$ \\
\hline 8 & Lack of accompanying person & $38(14.7)$ & $19(09.9)$ & $57(12.7)$ \\
\hline 9 & Lack of time & $27(08.3)$ & $16(10.5)$ & $43(09.6)$ \\
\hline 10 & God's will & $34(13.2)$ & $18(09.4)$ & $52(11.5)$ \\
\hline
\end{tabular}

Table 4: Reasons for delayed utilization of cataract surgery in study subjects.

*Multiple response (Figures in parenthesis denote percentages)

The predominant reason for delayed cataract surgery utilization was economic problem in both females and males (76.7\%). The another reasons were ignorance by patient (29.1\%), fear of surgery (26.4\%), ignorance by head of family (22.4\%) and suspicion about improvement of vision after surgery (21.5\%). Some subjects had given reasons as lack of accompanying person (12.7\%), fear of surgery causing death (10.7\%), Lack of time (09.6\%), it's God will(11.5\%) and lack of transport (06.7\%) (Table 4).

DISCUSSION: In the present study maximum study subjects were above 60 years of age as observed by Bhagwan J et al ${ }^{1}$ and Gyasi ME et al ${ }^{7}$. We observed $57.3 \%$ females and $42.7 \%$ males. Similar range of male and female cataract cases was observed by Gyasi ME et al ${ }^{7}$ and Limburg $\mathrm{H}$ et al ${ }^{8}$. Melese $\mathrm{M}$ et $\mathrm{al}^{9}$ of Ethiopia stated that as decision making was mainly in hands of husbands and male heads of households; these points to the need to gain support through promotional activities for eye care, especially surgery, for women. This kind of decision making is predominantly seen in Indian families and this is one of the reasons for delayed utilization of cataract surgery in females in India.

In our study, maximum study subjects (67.1\%) were from rural area and $32.9 \%$ from urban area. The association between rural residence and females using delayed cataract surgery was statistically significant $(\mathrm{P}<0.01)$. Dhaliwal $\mathrm{U}$ et $\mathrm{al}^{10}$ observed equal representation from urban and rural area for cataract cases presenting to a hospital, on the other hand Prasanna $\mathrm{T}$ et $\mathrm{al}^{3} \mathrm{reported}$ that utilization of cataract surgery was greater in urban area (59\%) compared with rural areas. The reason for this may be as they conducted study in JIPMER and Kurusukuppam area of Pondicherry, a major city in South India. As service providers are concentrated in major cities and towns so this has led to inadequate service provision to the rural poor ${ }^{4}$.

Dandona $\mathrm{R}$ et $\mathrm{al}^{5}$ stated that cases belonging to extreme lower and lower socioeconomic strata had 10 and five times higher risk of blindness respectively compared with those belonging to the upper socioeconomic status. Snellingen T et al11 study in Nepal revealed that low socioeconomic status was a barrier to the utilization of cataract surgery and our study also showed similar conclusions.

In this study $80.4 \%$ subjects were having unilateral blindness and $19.6 \%$ were having bilateral blindness. Among bilateral blindness 59.1\% subjects were females and 40.9\% were males. Females were having higher rates of bilateral blindness compared to males but this difference was not statistically significant ( $\mathrm{P}>0.05$ ). Bhagwan $\mathrm{J}$ et $\mathrm{al}^{1}$ found that there were $62.74 \%$ cases having unilateral blindness and $21.21 \%$ cases having bilateral blindness. Further he stated that bilateral cataracts cases were higher in rural areas (67.46\%) in comparison to urban areas (46.83\%). We observed the similar finding and the reason for this may be due to less awareness and less facilities for surgery in rural areas in comparison to urban areas. 
The predominant reason for delayed cataract surgery utilization was economical problem in both females and males (76.7\%). A study conducted in Upper East Region of Ghana found that cost was identified by $91 \%$ of respondents as the most important barrier to the uptake of cataract surgery. This was especially so with regard to direct cost which included cost of operation, drugs, transport and feeding 7 . Snellingen $\mathrm{T}$ et al ${ }^{11}$ in Nepal studied socioeconomic barriers to cataract surgery and observed that even with the promise of free treatment, only $24 \%$ actually had surgery within the following year. For this population the promise of free surgery did not seem to be the main motivational factor to accept treatment. Economic constraints as the main reason for not getting cataract surgery were also observed by other authors as well1,8,9,12.

Efforts to reduce indirect cost include conducting operations in the patient's own villages or facilitating transport to and from the surgical facility ${ }^{10}$. Providing accommodation for attendants closer to hospital facility and reducing the length of hospital stay can be other ways to reduce such barriers 4 . Next to the quality of services, it is likely that real changes in economic wealth and adult literacy in the communities particularly in the female population will be the most important determinants for improving the surgical uptake. Other effective measures are increased intersectoral collaboration with NGOs and corporate organization?.

We observed that fear of surgery was the reason given by $26.4 \%$ subjects. Fletcher AE et al 12 reported that fear was the reason most commonly given (by about one third of persons). This fear ranged from a common belief that treatment would damage the eyes to more diffuse anxieties, including a fear of death. A poor treatment outcome in somebody known to the person was identified as the source of fear in a small proportion (5\%) of persons not attending the eye camps.

Studies have shown that interaction with a patient who had undergone the operation could help in reducing fear and abolishing fatalistic beliefs that blindness was an inevitable part of old age or God's will10.

It is to be expected that as the experience in the community of successful cataract surgery increases, the elderly will become less afraid of surgical intervention and more prepared to accept that even in old age blind ness can be reversible 13.

Ignorance by patient themselves (29.1\%) and head of families $(22.4 \%)$ to undergo cataract surgery were the reasons even though subjects were unable to see in both unilateral and bilateral cataract blindness cases. Snellingen T et al11 observed that logistic constraints, i.e. guardian's willingness was the most important reason given for not accepting cataract surgery in $44.8 \%$ cases.

Some subjects gave reasons as lack of accompanying persons (12.7\%) and lack of transport (06.7\%) for delayed utilization of cataract surgery. Gyasi ME et al ${ }^{7}$ reported that lack of escort service was found to be the second most important barrier and this was attributed mainly to lack of accommodation for the escorts who usually come from the villages. Lack of accompanying persons and lack of transportation as a reason for not getting cataract surgery were also observed in other studies ${ }^{1,8,9,11 .}$

27.9\% females and $13.0 \%$ males were having suspicion about improvement of vision after surgery. Rotchford AP et al ${ }^{13}$ in rural South Africa noticed that several subjects were afraid that their vision might be made even worse after surgery. In a study conducted in Rural India, $5 \%$ of people gave poor outcomes in others as a reason for their non-use of eye services ${ }^{12}$.

Snellingen $\mathrm{T}$ et $\mathrm{al}^{11}$ observed that lack of time because of harvesting and planting (18.8\%) was the reason given for non use of eye care as found in the present study. 
Fletcher AE et al ${ }^{12}$ noticed that $13.9 \%$ people assumed their poor vision being "God's will" and our study also showed similar observation. A door-to-door survey on cataract blindness in persons 40 years and older was conducted in Mohadi Block, Bhandara District of Maharashtra State, India and it was found that more than $50 \%$ of the cataract blind persons were not interested in surgery. This emphasizes the definite and clear need for more, and especially better quality information, education and communication on eye care to reach the public ${ }^{8}$. To make cataract surgery more acceptable and within the reach of the patients, a definite propaganda has to be started. Communication packages need to be devised to educate especially the rural population on the importance of curable blindness and prompt advanced surgery.

\section{REFERENCES:}

1. Bhagwan J, Rastogi IM, Malik JS, Dhull CS. Knowledge, Attitude and Practices Regarding Cataract Surgery among Senile Cataract Cases in Haryana. Indian J Community Med 2006; 31(2):66-8.

2. Park K. Visual Impairment and Blindness. Park's Textbook of Preventive and Social Medicine. 22nd ed 2013; Bansaridas Bhanot publication, Jabalpur (India): 371-74.

3. Prasanna T, Rotti SB. Role of Socio-Economic Factors in Cataract Surgery Utilization in JIPMER Pondicherry. Indian J Community Med 2007;32(1):51-3.

4. Vaidyanathan K, Limburg H, Foster A, Pandey RM. Changing trends in barriers to cataract surgery in India. Bull World Health Organ 1999; 77:104-9.

5. Dandona R, Dandona L. Socioeconomic status and blindness. Br J Ophthalmol 2001; 85:1484-8.

6. Kulkarni AP, Baride JP, Doke PP and Mulay PY. Textbook of Community Medicine, 4th ed 2013. Vora Medical Publication, Mumbai: 31-32.

7. 7. Gyasi ME, Amoaku WMK and Asamany DK. Barriers to Cataract Surgical Uptake in the Upper East Region of Ghana. Ghana Med J 2007; 41(4):167-70. Available from: http://www.ncbi.nlm.nih.gov/pmc/articles/PMC2350119/ [Last accessed on 2013 June 10].

8. Limburg H, Vaidyanathan K, Pampattiwar K N. Cataract blindness on the rise? Results of a door-to-door examination in Mohadi. Indian J Ophthalmol 1996; 44:241-4.

9. Melese M, Alemayehu W, Friedlander E and Courtright P. Indirect costs associated with accessing eye care services as a barrier to service use in Ethiopia. Trop Med Int Health 2004; 9:426-31. Available from: http://onlinelibrary.wiley.com/doi/10.1111/j.13653156.2004.01205.x/pdf[Last accessed on 2013 June 10].

10. Dhaliwal U, Gupta SK. Barriers to the uptake of cataract surgery in patients presenting to a hospital. Indian J Ophthalmol 2007; 55:133-6.

11. Snellingen T, Shrestha BR, Gharti MP, Shrestha JK, Upadhyay MP, Pokhrel RP. Socioeconomic barriers to cataract surgery in Nepal: the south Asian cataract management study. Br J Ophthalmol 1998; 82:1424-8.

12. Fletcher AE, Donoghue M, Devavaram J, Thulasiraj RD, Scott S, Abdalla M et al. Low uptake of eye services in rural India: A challenge for programs of blindness prevention. Arch Ophthalmol 1999; 117:1393-9.

13. Rotchford AP, Rotchford KM, Mthethwa LP, Johnson GJ. Reasons for poor cataract surgery uptake - a qualitative study in rural South Africa. Trop Med Int Health 2002; 7: 288-92. 
Available from: http://onlinelibrary.wiley.com/doi/10.1046/j.1365-3156.2002.00850.x/pdf [Last accessed on 2013 June 12].

\section{AUTHORS: \\ 1. Gadekar R.D. \\ 2. Doibale M.K. \\ 3. Panzade S.W. \\ 4. Aswar N.R. \\ 5. Inam dar I.F. \\ 6. Domple V.K. \\ 7. Sonkar V.K. \\ 8. Kulkarni S.K.}

\section{PARTICULARS OF CONTRIBUTORS:}

1. Assistant Professor, Department of Community Medicine, Dr. S.C. Govt. Medical College, Nanded (M.S.)

2. Professor \& H.O.D, Department of Comm unity Medicine, Dr. S.C. Govt. Medical College, Nanded (M.S.)

3. Medical Officer, Rural Hospital, Naigaon District, Nanded (M.S.)

4. Associate Professor, Department of Community Medicine, Dr. S.C. Govt. Medical College, Nanded (M.S.)
5. Assistant Professor, Department of Community Medicine, Dr. S.C. Govt. Medical College, Nanded (M.S.)

6. Assistant Professor, Department of Community Medicine, Dr. S.C. Govt. Medical College, Nanded (M.S.)

7. Assistant Professor, Department of Community Medicine, Dr. S.C. Govt. Medical College, Nanded (M.S.)

8. Assistant Professor, Department of Community Medicine, Dr. S.C. Govt. Medical College, Nanded (M.S.)

\section{NAME ADDRESS EMAIL ID OF THE CORRESPONDING AUTHOR:}

Dr. Gad ekar R.D,

Ganga Building - 1, Class II Quarters,

Dr. S.C. Govt. Medical College Campus,

Vazirabad, Nanded - 431601.

Email - rdgadekarrd@gmail.com

Date of Submission: 26/07/2013.

Date of Peer Review: 27/07/2013.

Date of Acceptance: 15/10/2013.

Date of Publishing: 21/10/2013 